\title{
Clinical Values of Resting Electrocardiography in Patients with Known or Suspected Chronic Coronary Artery Disease: A Stress Perfusion Cardiac MRI Study
}

\author{
Yodying Kaolawanich \\ Mahidol University \\ Rawiwan Thongsongsang \\ Mahidol University \\ Thammarak Songsangjinda \\ Mahidol University \\ Thananya Boonyasirinant ( $\nabla$ drthananyaa@yahoo.com ) \\ Mahidol University
}

\section{Research Article}

Keywords: coronary artery disease, electrocardiography, myocardial ischemia, cardiac magnetic resonance

Posted Date: August 12th, 2021

DOI: https://doi.org/10.21203/rs.3.rs-627217/v1

License: (c) (1) This work is licensed under a Creative Commons Attribution 4.0 International License. Read Full License

Version of Record: A version of this preprint was published at BMC Cardiovascular Disorders on December 1st, 2021. See the published version at https://doi.org/10.1186/s12872-021-02440-5. 


\section{Abstract}

Background Electrocardiography (ECG) is an essential investigation in patients with chronic coronary artery disease (CAD). However, evidence regarding the diagnostic and prognostic value of ECG in this population is limited. Therefore, we sought to determine whether baseline ECG abnormalities were associated with myocardial ischemia and cardiac events in patients with known or suspected chronic CAD.

Methods Consecutive patients with known ( $n=146)$ or suspected chronic CAD ( $n=349)$ referred for adenosine stress cardiac magnetic resonance (CMR) between 2011 and 2014 were enrolled. Resting ECGs were classified as major, minor and no abnormalities. Predictors of myocardial ischemia on CMR and major adverse cardiac events (MACE) including cardiac death, nonfatal myocardial infarction, hospitalization for heart failure and late revascularization (>180 days after CMR) were evaluated.

Results Average age was $69 \pm 11$ years ( $51 \%$ men). One hundred and eighty-five patients $(37.4 \%)$ had major and 154 (31.1\%) had minor ECG abnormalities. In patients with suspected CAD, myocardial ischemia was present in 83 patients (23.8\%). Multivariable analysis demonstrated major ECG abnormality as the strongest predictor of myocardial ischemia (HR 2.88; 95\% $\mathrm{Cl} 1.69-4.92 ; \mathrm{p}<0.001)$. Adding ECG to clinical pretest probability models improved the prediction of myocardial ischemia in ROC analyses $(p=0.04)$. In the whole cohort $(n=495), 91$ MACE occurred during the median follow-up period of 4.8 years. Multivariable analysis showed that diastolic blood pressure, history of heart failure, prior revascularization, ischemia, myocardial scarring, and major ECG abnormality were independent predictors of MACE.

Conclusion Abnormal resting ECG is common in patients with known or suspected chronic CAD. ECG had important diagnostic and prognostic values in this population.

\section{Introduction}

Coronary artery disease (CAD) is one of the leading causes of morbidity and mortality worldwide ${ }^{(1)}$. Assessment of the pretest probability of CAD is crucial to select the most appropriate diagnostic test. The Diamond-Forrester (DF) model is one of the most common models used for this purpose, as recommended by the current guideline ${ }^{(2)}$. However, recent studies have demonstrated that the DF score was not adequate for modern populations of patients investigated for CAD ${ }^{(3-6)}$. The newly revised scores of the CAD consortium model may provide a more precise estimation of obstructive CAD ${ }^{(3-6)}$. Nevertheless, although the use of various pretest probability models as well as other noninvasive investigations have grown substantially, a landmark study demonstrated that only slightly more than onethird of patients without known disease who underwent elective cardiac catheterization had obstructive CAD (7). 
Electrocardiography (ECG) is a fundamental investigation in CAD patients, especially for acute coronary syndrome (ACS). ECG not only helps to establish the diagnosis of acute myocardial infarction (MI) but also provides valuable information on infarct location, results of reperfusion, as well as prognosis $(8,9)$. For chronic CAD, the current guideline recommended resting 12-lead ECG as an initial investigation in all patients with suspected $C A D{ }^{(2)}$. However, limited evidence exists regarding specific findings on resting ECG to provide a diagnostic clue in this population. Moreover, although ECG is a cheap and convenient investigation, information on resting ECG has never been included in any pretest probability model.

Resting ECG abnormality has been shown to be a strong predictor for mortality and major adverse cardiac events (MACE) in healthy subjects as well as for high-risk populations ${ }^{(10,11)}$. We hypothesized that resting ECG abnormality may have a diagnostic and prognostic role in patients with chronic CAD.

The primary objective of this study was to determine the diagnostic value of resting ECG to detect myocardial ischemia in patients with suspected chronic CAD who underwent adenosine stress cardiac magnetic resonance (CMR). The secondary objective was to evaluate the prognostic value of ECG in patients with known or suspected chronic CAD.

\section{Methods}

\section{Study Population}

Consecutive patients over 18 years old with suspected or documented CAD referred for adenosine stress CMR between May 2011 and December 2014 were enrolled (Figure 1). Documented CAD was defined using (i) history of $\mathrm{Ml}$, (ii) abnormal stress test, (iii) presence of significant CAD on coronary angiography $(>70 \%$ stenosis of three vessels or $>50 \%$ stenosis of the left main coronary artery), and (iv) history of coronary revascularization including percutaneous intervention or coronary artery bypass graphing. Patients with a diagnosis of recent ACS ( $<6$ months) were excluded due to dynamic change of ECG in this population. Patients with unreadable ECG or poor CMR image quality were also excluded. After exclusion, the group of patients with suspected CAD (Cohort $A$ ) were analyzed to determine the diagnostic value of resting ECG, while Cohort $B$ patients that included those with documented CAD (prior CMR) were analyzed to assess the prognostic role of ECG (Figure 1). The study was done in accordance with the Declaration of Helsinki. The institutional ethics committee (Siriraj Institutional Review Board [SIRB], Faculty of Medicine Siriraj Hospital, Mahidol University) approved this retrospective study and waived the need for additional written informed consent.

\section{ECG Data}

Twelve-lead ECG was obtained on the CMR date as a routine protocol for adenosine stress CMR. Each ECG was reviewed by two trained cardiologists and discordant results were adjudicated by a senior cardiologist. 
ECGs were coded according to the Minnesota Code (MC) and categorized into three groups as major, minor and no abnormalities based on the MC and according to previous publications ${ }^{(10-13)}$. Criteria for major ECG abnormalities were any of the following: Q-QS wave abnormalities (MC 1-1 to 1-2-8); left ventricular hypertrophy (LVH) (MC 3-1); complete bundle branch block or intraventricular block (MC 7-1-1, 7-2-1, 7-4 or 7-8); atrial fibrillation (AF) or atrial flutter (MC 8-3); or major ST-T changes (MC 4-1, 4-2, 5-1 and 5-2). Criteria for minor ECG abnormalities were minor ST-T changes (MC 4-3, 4-4, 5-3 and 5-4) or minor/isolated Q waves defined as MC 1-3 that are not codable as MI in the absence of any other major Q waves $(10,12)$. Patients with both major and minor abnormalities were classified as having major abnormalities. Patients without minor or major ECG abnormalities were classified as having no ECG abnormality.

\section{CMR Protocol $(14,15)$}

A CMR study was performed to assess cardiac function, myocardial perfusion and late gadolinium enhancement (LGE) using a 1.5 Tesla Philips Achieva XR scanner (Philips Medical Systems, Best, The Netherlands).

The cardiac functional study was performed by acquiring the images using a steady-state free precession (SSFP) technique in a vertical long axis, 2-chamber, 4-chamber and multiple slice short-axis views.

Parameters for cardiac function were echo time (TE) 1.8 milliseconds (ms), repetitive time (TR) $3.7 \mathrm{~ms}$, number of excitations 2, field of view (FOV) $390 \times 312$ mm, matrix $256 \times 240$, reconstruction pixels $1.52 \times$ 1.21 , slide thickness $8 \mathrm{~mm}$ and flip angle 70 degrees.

The myocardial first-pass perfusion study was performed by injection of $0.05 \mathrm{mmol} / \mathrm{kg}$ of gadolinium contrast agent (Magnevist, Bayer Schering Pharma, Berlin, Germany) at a rate of $4 \mathrm{ml} / \mathrm{s} \mathrm{immediately} \mathrm{after}$ a 4-minute infusion of $140 \mathrm{mcg} / \mathrm{kg} / \mathrm{min}$ of adenosine. Three short-axis slices of basal, mid and apical left ventricular (LV) levels were acquired using an ECG-triggered SSFP, inversion-recovery, single-shot, turbo gradient-echo sequence. Image parameters were TE $1.32 \mathrm{~ms}$, TR $2.6 \mathrm{~ms}$, flip angle 50 degrees, slice thickness $8 \mathrm{~mm}$, FOV $270 \mathrm{~mm}$ and reconstructed FOV $320 \mathrm{~mm}$.

LGE images were acquired approximately 10 minutes after an additional bolus of gadolinium ( 0.1 $\mathrm{mmol} / \mathrm{kg}$, rate $4 \mathrm{ml} / \mathrm{s}$ ) by the 3D segmented-gradient-echo inversion-recovery sequence. LGE images were acquired in multiple short-axis slices at levels similar to the functional images, long axis, 2-chamber and 4-chamber view. Parameters for LGE study were TE $1.25 \mathrm{~ms}$, TR $4.1 \mathrm{~ms}$, flip angle 15 degrees, FOV $303 \mathrm{x}$ $384 \mathrm{~mm}$, matrix $240 \times 256$, in-plane resolution $1.26 \times 1.5 \mathrm{~mm}$, slice thickness $8 \mathrm{~mm}$ and 1.5 sensitivityencoding factor.

\section{Image Analysis $(15,16)$}


Standard LV volumes, mass and ejection fraction (EF) were quantitatively measured from the stack of short-axis SSFP cine images.

The perfusion and LGE images were analyzed using visual assessment and consensus by two CMRtrained physicians blinded to clinical and follow-up data. Segmentation of each slice was performed

according to the recommendation of the American Heart Association ${ }^{(17)}$. Perfusion images were read, and each of the 16 segments was visualized (segment-17 at the apex was not visualized). Inducible ischemia was defined as a subendocardial perfusion defect that (i) persisted beyond peak myocardial enhancement and for several RR intervals, (ii) was more than two pixels wide, (iii) followed one or more coronary arteries, and (iv) showed absence of LGE in the same segment ${ }^{(16)}$. Dark-banding artifacts were recorded if an endocardial dark band appeared at the arrival of contrast in the LV cavity before contrast arrival in the myocardium ${ }^{(16)}$. LGE images were also analyzed using visual assessment. LGE was considered present only if confirmed on both the short-axis and at least one other orthogonal plane ${ }^{(16)}$.

\section{Clinical Follow-up}

Follow-up data were collected from clinical visits and medical records. Clinical event adjudication was completely blinded to clinical and CMR data. Patients were followed up for MACE. MACE was defined as the composite outcomes of cardiac mortality, nonfatal MI, hospitalization for unstable angina, hospitalization for heart failure and late coronary revascularization (>180 days after CMR). Need for revascularization therapy within 180 days after the CMR was considered to be triggered by the CMR results and therefore censored from analysis. Cardiac mortality included death resulting from acute $\mathrm{MI}$, heart failure, sudden cardiac death, or death due to complications in cardiac procedures ${ }^{(18)}$.

\section{Statistical Analysis}

Statistical analyses were performed using IBM SPSS Statistics for Windows version 20.0 (IBM Corp., Armonk, NY, USA). Continuous variables with normal distribution were presented as mean \pm standard deviation (SD), and continuous variables with non-normal distribution were presented as median and interquartile ranges. The normality of the distribution of variables was examined by the KolmogorovSmirnov test. Categorical variables were present as absolute numbers and percentages. Normally distributed continuous data of multiple ( $>2$ ) groups were compared using one-way analysis of variance. Non-normally distributed continuous data of multiple (>2) groups were compared using the KruskalWallis test. Continuous variables between two groups were compared using the Student's unpaired t-test or Mann-Whitney U test. Categorical data were compared by the chi-squared test or Fisher's exact test, as appropriate.

To analyze the predictors of myocardial ischemia, a Cox-regression analysis was performed to assess univariable predictors from baseline characteristics and ECG. Variables with a $p$-value $<0.05$ on univariable analysis were entered into the multivariable analysis. The incremental value of ECG in 
predicting myocardial ischemia was assessed by comparing the area under the receiver operating characteristic (ROC) curves for the DF model and clinical model of CAD consortium with and without the addition of ECG.

Kaplan-Meier plots were used to compare the proportion of patients in each group who had an event during follow-up. The log-rank test was used to compare groups on the Kaplan-Meier analysis. To analyze the predictors of MACE, a Cox-regression analysis was performed to assess univariable predictors from baseline characteristics and CMR parameters. Variables with a $\mathrm{p}$-value $<0.05$ on univariable analysis were entered into the multivariable analysis. To assess the incremental prognosis values of multiple major ECG abnormalities, global chi-square values were calculated after adding predictors in the following order: clinical, numbers of major ECG abnormalities (1, 2 and more than 2 findings).

The hazard ratios (HRs) and 95\% confidence intervals (Cls) of the outcomes were calculated, with a pvalue $<0.05$ considered statistically significant.

\section{Results}

\section{Patient Characteristics}

Among the 514 patients with known or suspected CAD that were enrolled (Figure 1), 19 were excluded: ten had a history of recent ACS, 3 had unreadable ECGs, 2 had poor CMR image quality and 4 had a follow-up period of less than 6 months. Thus, 349 patients with suspected CAD (Cohort A) were included in the final analysis of the diagnostic value of the ECG. After adding 146 patients with known CAD (7 had a history of MI), a total of 495 patients (Cohort B) were included in the final analysis of the prognostic value of the ECG (Figure 1).

Clinical characteristics of patients with suspected CAD (Cohort A, $n=349$ ) are listed in Table 1. The average age was 68.3 years, $46.7 \%$ were men. The most common presenting symptom was atypical angina (30.4\%). The pretest probability of obstructive CAD was intermediate (20.3\% by the DF model, and $30.3 \%$ by clinical model of CAD consortium). The average LVEF was $68.8 \%$. Myocardial ischemia was present in 83 patients $(23.8 \%)$ and LGE was detected in 59 patients $(16.9 \%)$. No microvascular obstruction (representing recent $\mathrm{MI}$ ) was detected by LGE-CMR.

Table 1

Clinical Characteristics of Patients with Suspected CAD (Cohort A). 


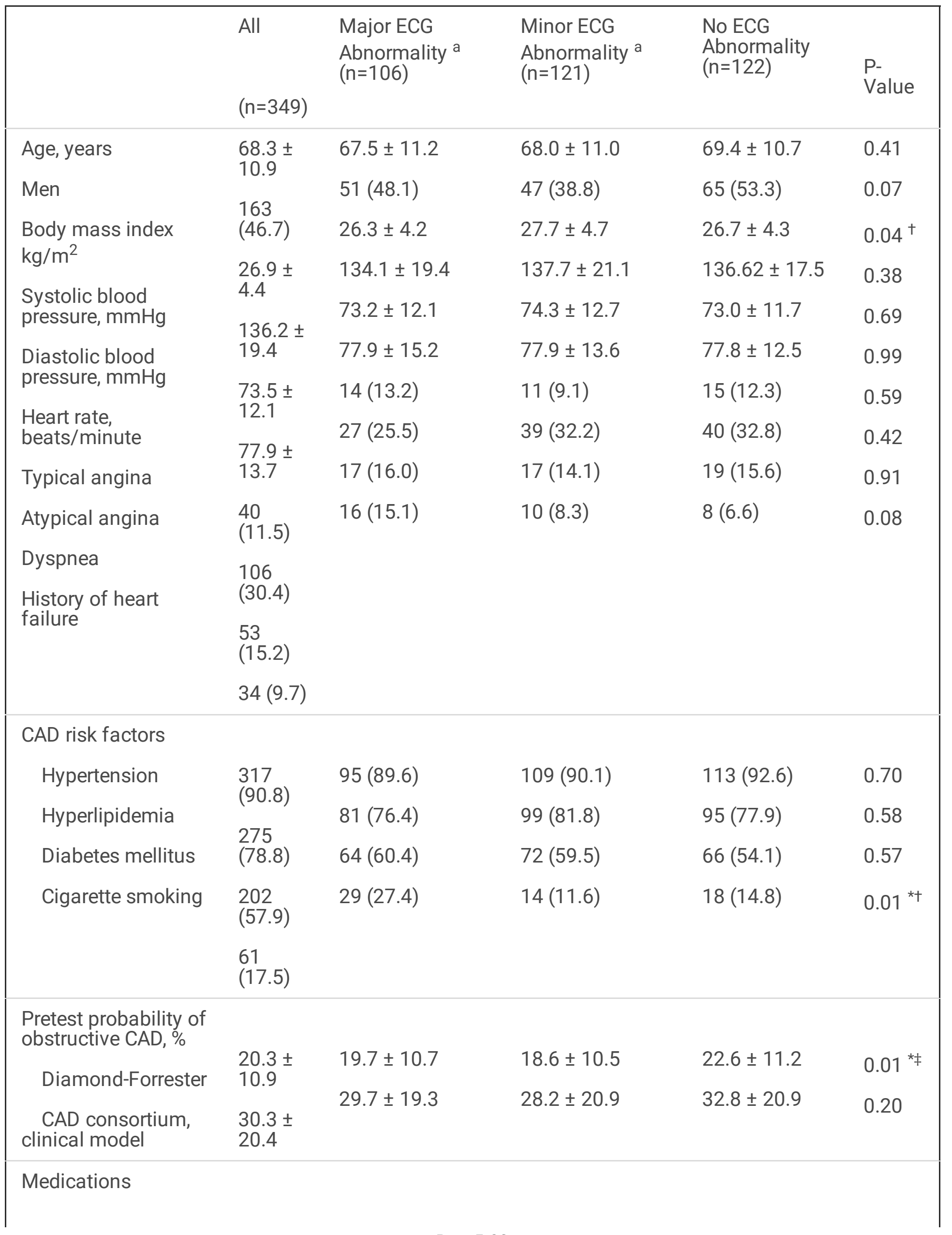




\begin{tabular}{|c|c|c|c|c|c|}
\hline ACEI or ARB & 150 & $49(46.2)$ & $51(42.2)$ & $50(41.0)$ & 0.71 \\
\hline Antiplatelet & & $49(46.2)$ & $50(41.3)$ & $53(43.4)$ & 0.76 \\
\hline Beta blocker & $(43.6)$ & $48(45.3)$ & $46(38.0)$ & $61(50.0)$ & 0.17 \\
\hline Calcium channel & 155 & $30(28.3)$ & $41(33.9)$ & $49(40.2)$ & 0.17 \\
\hline DIVChel & & $50(47.2)$ & $61(50.4)$ & $63(51.6)$ & 0.79 \\
\hline Statin & $\begin{array}{l}120 \\
(34.4)\end{array}$ & & & & \\
\hline & $\begin{array}{l}174 \\
(49.9)\end{array}$ & & & & \\
\hline CMR & & & & & \\
\hline LV end diastolic & $74.5 \pm$ & $84.3 \pm 35.0$ & $70.6 \pm 18.1$ & $70.0 \pm 15.5$ & $<0.001$ \\
\hline volume index, $\mathrm{ml} / \mathrm{m}^{2}$ & & $35.1 \pm 34.6$ & $23.7 \pm 17.6$ & $19.6 \pm 9.9$ & \\
\hline $\begin{array}{l}\text { LV end systolic } \\
\text { volume index, } \mathrm{ml} / \mathrm{m}^{2}\end{array}$ & $\begin{array}{l}25.8 \pm \\
23.3\end{array}$ & $64.1 \pm 16.8$ & $68.7 \pm 12.3$ & $72.9 \pm 8.9$ & $\begin{array}{l}<0.001 \\
*+\neq\end{array}$ \\
\hline LV ejection & $\begin{array}{l}68.8 \pm \\
13.3\end{array}$ & $60.8 \pm 23.1$ & $47.0 \pm 11.7$ & $48.2 \pm 13.4$ & $<0.001$ \\
\hline fraction, \% & & $39(36.8)$ & $23(19.0)$ & $21(17.2)$ & ${ }^{\star \star}+$ \\
\hline $\begin{array}{l}\text { LV mass index, } \\
\mathrm{g} / \mathrm{m}^{2}\end{array}$ & $\begin{array}{l}51.6 \pm \\
17.6\end{array}$ & $39(36.8)$ & $13(10.7)$ & $7(5.7)$ & $\begin{array}{l}<0.001 \\
\star \star \neq\end{array}$ \\
\hline $\begin{array}{l}\text { Myocardial } \\
\text { ischemia }\end{array}$ & $\begin{array}{l}83 \\
(23.8)\end{array}$ & & & & 0.001 \\
\hline $\begin{array}{l}\text { Late gadolinium } \\
\text { enhancement }\end{array}$ & $\begin{array}{l}59 \\
(16.9)\end{array}$ & & & & $\begin{array}{l}<0.001 \\
\star+\end{array}$ \\
\hline Values are numbers & centas & mean $\pm s t$ & viation. Bol & s are $<0.05$ & \\
\hline $\begin{array}{l}\text { ACEI = angiotensin-co } \\
\text { artery disease; } \mathrm{CMR}=\end{array}$ & $\begin{array}{l}\text { lerting } \epsilon \\
\text { ardiac } n\end{array}$ & $\begin{array}{l}\text { me inhibitor; } \\
\text { netic resonan }\end{array}$ & $\begin{array}{l}\text { angiotensin II } \\
=\text { electrocarc }\end{array}$ & $\begin{array}{l}\text { or blocker; CAL } \\
\text { hic; LV = left v }\end{array}$ & $\begin{array}{l}\text { oronary } \\
\text { cular. }\end{array}$ \\
\hline a See "Methods" secti & for def & ons of major & nor ECG abnc & & \\
\hline $\begin{array}{l}{ }^{\star} \text { Major ECG abnorma } \\
\text { abnormality; }{ }^{\ddagger} \text { minor }\end{array}$ & $\begin{array}{l}\text { y versus } \\
G \text { abnor }\end{array}$ & $\begin{array}{l}\text { ECG abnorm } \\
\text { lity versus no }\end{array}$ & $\begin{array}{l}\text { najor ECG ab } \\
\text { onormality. }\end{array}$ & ity versus min & CG \\
\hline
\end{tabular}

All ECGs were performed on the same day as CMR. No patient reported ongoing chest pain during ECG.

Major ECG abnormality was detected in 106 patients (30.4\%) including Q-Qs wave $(n=34)$, LV hypertrophy $(n=25)$, complete bundle branch block/intraventricular block $(n=26)$, atrial fibrillation $(n=6)$ and major STT change $(n=36)$. Minor ECG abnormality was detected in 121 patients $(34.6 \%)$ including minor ST-T change $(n=68)$ and minor/isolated Q wave $(n=71)$. Among a random sample of $10 \%$ of ECGs, Kappa values for the categorization described were 0.85 for major, 0.80 for minor and 0.81 for no ECG abnormalities. 
There was no significant difference in the pretest probability of obstructive CAD using the clinical model of CAD consortium ( $p=0.20$ ) among the three groups. However, using the DF model, patients with no ECG abnormality had a higher pretest probability of obstructive CAD than those with major or minor abnormality $(p=0.01)$. Patients with major ECG abnormality had a higher prevalence of cigarette smoking compared with minor or no abnormality. Patients with major ECG abnormality also had significantly higher LV volume, higher LV mass index and lower LVEF than minor and no ECG abnormality $(p<0.001$ for all). Moreover, patients with major ECG abnormality demonstrated a significantly higher prevalence of myocardial ischemia and LGE ( $p<0.001$ and $p=0.001$, respectively).

\section{Predictors of Myocardial Ischemia}

Table 2 demonstrates the univariable and multivariable analyses of the predictors of myocardial ischemia. Men, diabetes mellitus, cigarette smoking, typical angina, both models of pretest probability of obstructive CAD, taking antiplatelets and major ECG abnormality were predictors of myocardial ischemia in the univariable analysis. For both models of the multivariable analysis (model 1 using the DF and model 2 using the clinical model of CAD consortium), major ECG abnormality was the strongest predictor of myocardial ischemia $(p<0.0001)$ Minor ECG abnormality was not associated with myocardial ischemia.

Table 2

Predictors of Myocardial Ischemia. 


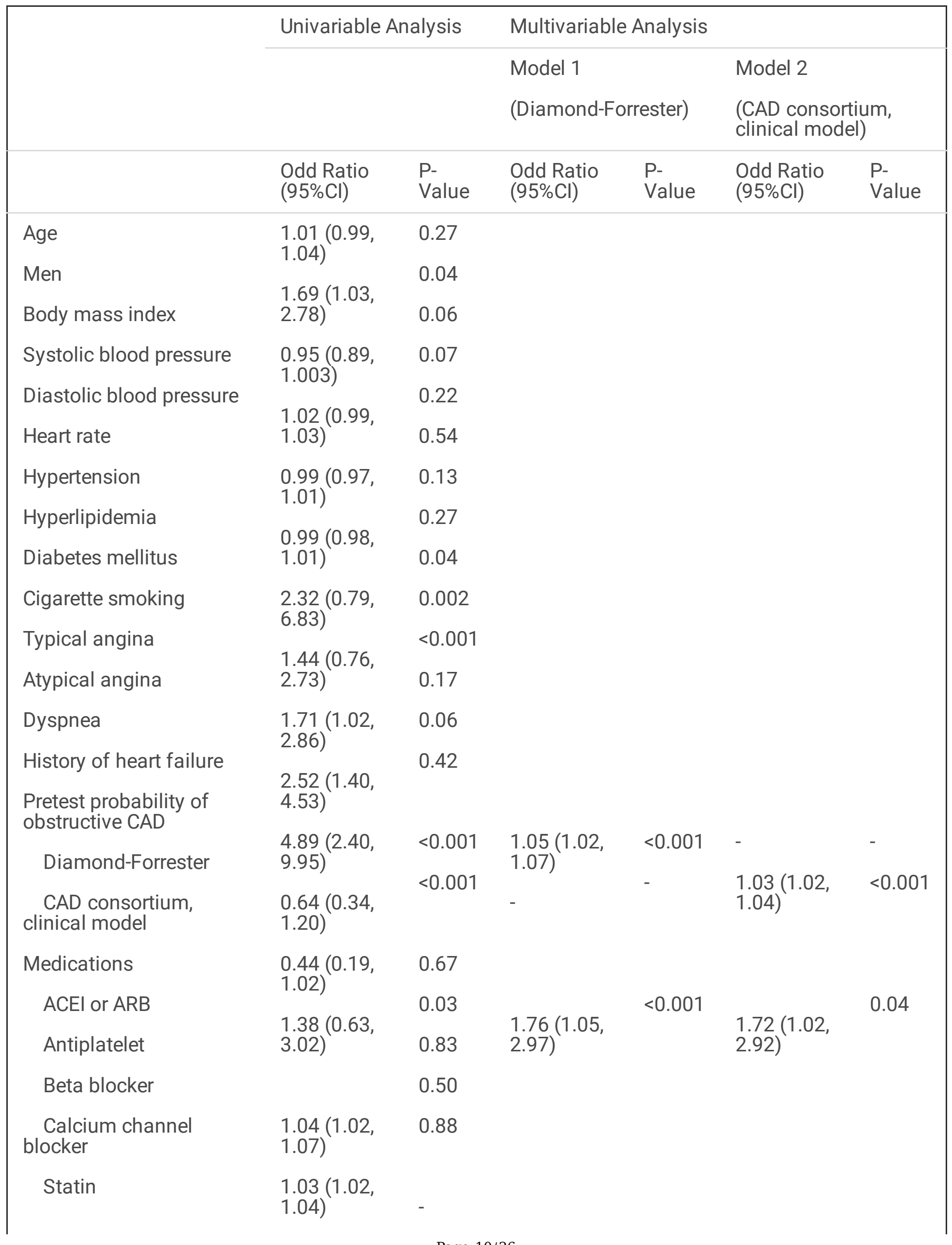




\begin{tabular}{|c|c|c|c|c|}
\hline ECG & & $<0.001$ & & \\
\hline $\begin{array}{l}\text { No ECG abnormality } \\
\text { (reference) }\end{array}$ & $\begin{array}{l}0.90(0.54 \\
1.48)\end{array}$ & 0.72 & $\begin{array}{l}2.88(1.69 \\
4.92)\end{array}$ & $\begin{array}{l}2.93(1.70 \\
5.03)\end{array}$ \\
\hline $\begin{array}{c}\text { Major ECG } \\
\text { abnormality a }\end{array}$ & $\begin{array}{l}1.76(1.07 \\
2.89)\end{array}$ & & & \\
\hline $\begin{array}{c}\text { Minor ECG } \\
\text { abnormality a }\end{array}$ & $\begin{array}{l}0.95(0.58 \\
1.56)\end{array}$ & & & \\
\hline & $\begin{array}{l}0.84(0.49 \\
1.42)\end{array}$ & & & \\
\hline & $\begin{array}{l}1.04(0.64 \\
1.70)\end{array}$ & & & \\
\hline & 1.00 & & & \\
\hline & $\begin{array}{l}2.80(1.52, \\
5.17)\end{array}$ & & & \\
\hline & $\begin{array}{l}1.13(0.59, \\
2.17)\end{array}$ & & & \\
\hline
\end{tabular}

Bold values are $<0.05$

$\mathrm{Cl}=$ confidence interval; other abbreviations as in Table 1 .

a See "Methods" section for definitions of major and minor ECG abnormalities.

To determine whether any ECG findings were more specific for myocardial ischemia, we performed a stratified analysis by types of ECG. Supplemental Table 1 shows an exploratory analysis of specific ECG findings and the risk of myocardial ischemia. Highest risk of myocardial ischemia was observed in patients with Q-Qs wave (47\%; $95 \% \mathrm{Cl} 29 \%$ to $65 \%$ ) and major ST-T changes (47\%; $95 \% \mathrm{Cl} 30$ to $64 \%$ ). Both types of minor ECG abnormality (minor ST-T change and minor/isolated Q wave) showed a similar risk of myocardial ischemia compared with no ECG abnormality (range 17 to $19 \%$ ).

We also performed additional analyses using two models of pretest probability of obstructive CAD in predicting myocardial ischemia with and without ECG data to explore how adding ECG data might improve the risk prediction for myocardial ischemia. The area under the curve for predicting myocardial ischemia using the DF score was 0.64 , which increased to 0.70 when adding ECG data $(p=0.04)$ (Figure $2 A)$. Similar to the clinical model of CAD consortium, after adding ECG data, the area under the curve increased from 0.67 to $0.72(p=0.04)$ (Figure 2B).

\section{Follow-up Results}


Cohort B was composed of 349 patients with suspected and 146 patients with known CAD. During a median follow-up of 4.8 years $(2.9,5.6$ years), 91 MACE (18.4\%) occurred. The rate of specific cardiac events is listed in Supplemental Table 2.

Table 3 shows the clinical characteristics of patients with and without MACE. Patients with MACE were more likely to have a history of $\mathrm{CAD}, \mathrm{MI}$, heart failure, coronary revascularization, major ECG abnormality as well as lower LVEF, myocardial ischemia and LGE. Figure 3 demonstrates the Kaplan-Meier estimates of MACE for patients without ECG abnormalities versus major and minor ECG abnormalities. Patients with major ECG abnormalities had a significantly higher rate of MACE compared to those with no ECG abnormality (HR 2.48; 95\% Cl 1.50-4.09; $\mathrm{p}<0.001$ ). Patients with minor ECG abnormalities had similar rates of MACE compared with those with no ECG abnormality (HR 0.65; 95\% Cl 0.33-1.28; $\mathrm{p}=0.22$ ). Multivariable analysis showed diastolic blood pressure, prior revascularization, history of heart failure, major ECG abnormality, myocardial ischemia and LGE as independent predictors of MACE (Table 4).

Given that several patients may have more than one abnormality of ECG, we performed an additional analysis to determine whether numbers of major ECG abnormalities could provide an incremental prognostic value over the clinical model in hierarchical order (Figure 4). The clinical model included age, male gender, diastolic blood pressure, history of heart failure and prior revascularization. Multiple ECG abnormalities provided an incremental prognostic value over clinical data plus one ECG abnormality $(\mathrm{p}<0.05)$.

Table 3

Clinical Characteristics of Patients with and without MACE (Cohort B). 


\begin{tabular}{|c|c|c|c|c|}
\hline & $\begin{array}{l}\text { All } \\
(n=495)\end{array}$ & $\begin{array}{l}\text { MACE } \\
(n=91)\end{array}$ & $\begin{array}{l}\text { No MACE } \\
(n=404)\end{array}$ & P-Value \\
\hline Age, years & $68.9 \pm 10.6$ & $70.5 \pm 10.5$ & $68.5 \pm 10.7$ & 0.10 \\
\hline Men & $253(51.1)$ & $49(53.9)$ & $204(50.5)$ & 0.56 \\
\hline Body mass index, $\mathrm{kg} / \mathrm{m}^{2}$ & $26.6 \pm 4.4$ & $25.9 \pm 4.2$ & $26.8 \pm 4.4$ & 0.08 \\
\hline Systolic blood pressure, $\mathrm{mmHg}$ & $137.0 \pm 19.9$ & $137.4 \pm 22.8$ & $136.9 \pm 19.1$ & 0.84 \\
\hline Diastolic blood pressure, $\mathrm{mmHg}$ & $73.0 \pm 12.0$ & $69.9 \pm 11.7$ & $73.7 \pm 12.0$ & 0.01 \\
\hline Heart rate, beats/minute & $77.1 \pm 13.7$ & $76.8 \pm 14.4$ & $77.1 \pm 13.6$ & 0.83 \\
\hline \multicolumn{5}{|l|}{ CAD risk factors } \\
\hline Hypertension & $449(90.7)$ & $86(94.5)$ & $363(89.9)$ & 0.17 \\
\hline Hyperlipidemia & $406(82.0)$ & $81(89.0)$ & $325(80.5)$ & 0.06 \\
\hline Diabetes mellitus & $283(57.2)$ & $59(64.8)$ & $224(55.4)$ & 0.10 \\
\hline Cigarette smoking & $91(18.4)$ & $23(25.3)$ & $68(16.8)$ & 0.06 \\
\hline \multicolumn{5}{|l|}{ Clinical history } \\
\hline History of CAD & $143(28.9)$ & $52(57.1)$ & $91(22.5)$ & $<0.001$ \\
\hline History of myocardial infarction & $25(5.1)$ & $9(9.9)$ & $16(4.0)$ & 0.03 \\
\hline Prior revascularization & $99(20.0)$ & $36(39.6)$ & $63(15.6)$ & $<0.001$ \\
\hline History of heart failure & $55(11.1)$ & $25(27.5)$ & $30(7.4)$ & $<0.001$ \\
\hline \multicolumn{5}{|l|}{ Medications } \\
\hline ACEI or ARB & $231(46.7)$ & $51(56.0)$ & $180(44.6)$ & 0.04 \\
\hline Antiplatelet & $267(53.9)$ & $59(64.8)$ & $208(51.5)$ & 0.02 \\
\hline Beta blocker & $250(50.5)$ & $50(55.0)$ & $200(49.5)$ & 0.35 \\
\hline Calcium channel blocker & $160(32.3)$ & $27(29.7)$ & $133(32.9)$ & 0.55 \\
\hline Statin & $277(56.0)$ & $59(64.8)$ & $218(54.0)$ & 0.06 \\
\hline \multicolumn{5}{|l|}{$\mathrm{ECG}^{\mathrm{a}}$} \\
\hline QRS axis, degree & $25.4 \pm 37.7$ & $22.2 \pm 35.7$ & $26.1 \pm 38.1$ & 0.46 \\
\hline No ECG abnormality & $156(31.5)$ & $21(23.1)$ & $135(33.4)$ & 0.06 \\
\hline Major ECG abnormality & $185(37.4)$ & $56(61.5)$ & 129 (31.9) & $<0.001$ \\
\hline Q-Qs wave & $76(15.4)$ & $25(27.5)$ & $51(12.6)$ & $<0.001$ \\
\hline LV hypertrophy & $43(8.7)$ & $17(18.7)$ & $26(6.4)$ & $<0.001$ \\
\hline
\end{tabular}




$\begin{array}{|lllll|}\text { Complete bundle branch/IVB } & 38(7.7) & 6(6.6) & 32(7.9) & 0.67 \\ \text { Atrial fibrillation/flutter } & 12(2.4) & 6(6.6) & 6(1.5) & 0.01 \\ \text { Major ST-T changes } & 64(12.9) & 25(27.5) & 39(9.7) & <0.001 \\ \text { Minor ECG abnormality } & 154(31.1) & 14(15.4) & 140(34.7) & <0.001 \\ \text { Minor ST-T changes } & 95(19.2) & 11(12.1) & 84(20.8) & 0.06 \\ \text { Minor/isolated Q wave } & 86(17.4) & 6(6.6) & 80(19.8) & 0.003 \\ \text { CMR } & & & & \\ \text { LV end diastolic volume index, } \mathrm{ml} / \mathrm{m}^{2} & 77.6 \pm 26.7 & 91.9 \pm 37.6 & 74.4 \pm 22.5 & <0.001 \\ \text { LV end systolic volume index, } \mathrm{ml} / \mathrm{m}^{2} & 29.3 \pm 26.6 & 45.0 \pm 38.3 & 25.7 \pm 21.7 & <0.001 \\ \text { LV ejection fraction, \% } & 66.5 \pm 15.0 & 58.2 \pm 19.9 & 68.4 \pm 13.0 & <0.001 \\ \text { LV mass index, g/m }{ }^{2} & 53.1 \pm 17.4 & 62.0 \pm 21.0 & 51.0 \pm 15.8 & <0.001 \\ \text { Myocardial ischemia } & 153(30.9) & 49(53.9) & 104(25.7) & <0.001 \\ \text { Late gadolinium enhancement } & 146(29.4) & 51(56.0) & 95(23.5) & <0.001 \\ \text { Values are numbers (percentages) or mean } \pm \text { standard deviation. Bold values are <0.05. } & \\ \text { IVB = intraventricular block; MACE = major adverse cardiac events; other abbreviations as in Table 1. } \\ \text { a See "Methods" section for definitions of major and minor ECG abnormalities. }\end{array}$

Table 4

Predictors of MACE. 


\begin{tabular}{|c|c|c|c|c|}
\hline & \multicolumn{2}{|c|}{ Univariable Analysis } & \multicolumn{2}{|c|}{ Multivariable Analysis } \\
\hline & $\mathrm{HR}(95 \% \mathrm{Cl})$ & P-Value & $\mathrm{HR}(95 \% \mathrm{Cl})$ & P-Value \\
\hline Age & $1.02(0.99,1.04)$ & 0.13 & & \\
\hline Men & $1.06(0.54,2.05)$ & 0.87 & & \\
\hline Body mass index & $0.95(0.91,1.001)$ & 0.05 & & \\
\hline Systolic blood pressure & $0.99(0.98,1.01)$ & 0.88 & & \\
\hline Diastolic blood pressure & $0.97(0.96,0.99)$ & 0.003 & $0.98(0.96,0.99)$ & 0.02 \\
\hline Heart rate & $0.99(0.98,1.01)$ & 0.92 & & \\
\hline Hypertension & $0.79(0.28,2.23)$ & 0.65 & & \\
\hline Hyperlipidemia & $0.93(0.39,2.24)$ & 0.87 & & \\
\hline Diabetes mellitus & $1.43(0.73,2.83)$ & 0.30 & & \\
\hline Cigarette smoking & $1.05(0.46,2.40)$ & 0.91 & & \\
\hline History of CAD & $3.56(2.36,5.40)$ & $<0.001$ & & \\
\hline History of myocardial infarction & $2.55(1.28,5.08)$ & 0.01 & & \\
\hline Prior revascularization & $3.09(2.03,4.71)$ & $<0.001$ & $2.59(1.65,4.09)$ & $<0.001$ \\
\hline History of heart failure & $3.60(2.27,5.70)$ & $<0.001$ & $3.31(2.01,5.44)$ & $<0.001$ \\
\hline \multicolumn{5}{|l|}{ Medications } \\
\hline ACEl or ARB & $0.90(0.46,1.75)$ & 0.75 & & \\
\hline Antiplatelet & $1.60(0.80,3.21)$ & 0.19 & & \\
\hline Beta blocker & $0.96(0.50,1.87)$ & 0.91 & & \\
\hline Calcium channel blocker & $1.20(0.61,2.39)$ & 0.60 & & \\
\hline Statin & $1.85(0.90,3.77)$ & 0.09 & & \\
\hline \multicolumn{5}{|l|}{ ECG } \\
\hline No ECG abnormality (reference) & 1.00 & - & & \\
\hline Major ECG abnormality ${ }^{a}$ & $2.48(1.50,4.09)$ & $<0.001$ & $1.65(1.03,2.63)$ & 0.03 \\
\hline Minor ECG abnormality a & $0.65(0.33,1.28)$ & 0.22 & & \\
\hline \multicolumn{5}{|l|}{ CMR } \\
\hline LV end diastolic volume index & $1.01(1.004,1.02)$ & 0.01 & & \\
\hline LV end systolic volume index & $1.01(1.003,1.02)$ & 0.01 & & \\
\hline LV ejection fraction & $\begin{array}{c}0.97(0.96,0.98) \\
\text { Page } 15 / 26\end{array}$ & $<0.001$ & & \\
\hline
\end{tabular}


LV mass index

Myocardial ischemia

Late gadolinium enhancement

Abbreviations as in Table 1 to 3.

a See "Methods" section for definitions of major and minor ECG abnormalities

\section{Discussion}

Results of this study demonstrated that (i) the presence of major ECG abnormality was associated with a $\approx 3$-fold increased likelihood of myocardial ischemia in patients with an intermediate pretest probability of obstructive CAD, (ii) ECG provided an incremental diagnostic value over clinical pretest probability models, and (iii) ECG was an independent prognostic predictor for MACE in patients with known or suspected CAD.

Several previous studies reported an association between ECG abnormalities and cardiovascular outcomes $(10,11)$. Auer et al. conducted a population-based study of 2,192 older adults. They found that the prevalence of baseline ECG abnormality was $36 \%$ and associated with significantly increased risks of coronary heart disease events ${ }^{(10)}$. Krittayaphong et al. demonstrated that ECG abnormalities including AF, Q-QS wave, intraventricular conduction delay and LVH increased the risk of MACE in patients with high cardiovascular risk ${ }^{(11)}$. However, these studies were conducted on patients without CAD. ECG is an essential investigation to make a diagnosis of STEMI, as well as providing important prognostic value ( 8 , 9). Nevertheless, evidence regarding the diagnostic and prognostic role of resting ECG in patients with chronic CAD is limited.

Farhan et al. demonstrated an association between $\mathrm{T}$ wave inversion in lead $\mathrm{V} V \mathrm{~L}$ and significant stenosis of mid LAD by invasive coronary angiography in patients with stable angina ${ }^{(19)}$. However, a relatively small number of populations precluded an accurate multivariate analysis to compare $T$ wave inversion in lead aVL with other ECG findings ${ }^{(19)}$. Our data demonstrated that resting ECG abnormality was common in patients with known or suspected chronic CAD (37\% for major and $31 \%$ for minor abnormality). The prevalence was similar to the study of Farhan et al ${ }^{(19)}$. Our results demonstrated that major ECG abnormality was a strong and independent predictor of myocardial ischemia. Specifically, major ST-T change and Q-QS wave were the most predictive values.

In patients with chest pain, guidelines recommend initial diagnostic evaluation by assessment of an individual's pretest probability of CAD to make decisions regarding further diagnostic testing ${ }^{(2)}$. Multiple risk scores have been developed to systematize risk assessment based on clinical history including the 
DF and CAD consortium models ${ }^{(5,20)}$. However, recent studies demonstrated that the DF score overestimated the probability of CAD, especially in women ${ }^{(20)}$. The CAD consortium clinical model appeared to improve the prediction in low-risk patients but the use of this model requires caution in a high-risk population ${ }^{(6)}$. In our study, both the DF score and the CAD consortium clinical model overestimated myocardial ischemia using CMR as a reference. We used adenosine stress CMR to define obstructive $C A D$ and this may cause some degree of discrepancies due to the referral bias of patients who underwent CMR. However, our data showed that ECG could add a predictive value over pretest probability score alone as a clinical implication of ECG in this population.

Minor ECG abnormality was common with prevalence of up to $40 \%$ in patients with abnormal signs or symptoms of CVD (21). Daviglus et al. found that persistent nonspecific ST-T abnormality was associated with cardiovascular mortality in 1,673 healthy men ${ }^{(22)}$. In our study, the prevalence of minor ECG abnormality (minor ST-T change or minor/isolated Q wave) was $31 \%$. However, in our study, minor ECG abnormalities were not associated with myocardial ischemia or MACE, due to differences in the definition of minor ECG abnormality and number of patients. A larger study may be required to confirm the results.

A number of studies demonstrated the prognostic value of ECG abnormality in various populations including healthy elderly and patients with hypertension and diabetes $(10,23,24)$. Abnormal ECG was found to be consistently associated with future cardiovascular events $(10,23,24)$. Our study showed a prognostic value of major ECG in patients with known or suspected CAD. The numbers of major ECG abnormalities also provided additional prognostic value over single abnormality. Studies regarding the prognostic value of resting ECG in patients with chronic CAD are limited. However, our result was similar to Jeger et al who demonstrated that resting ECG abnormalities including ST depression and faster heart rate were associated with cardiovascular events in patients with CAD who underwent major noncardiac surgery ${ }^{(25)}$. Q wave on resting ECG appears to represent previous MI. However, recent studies demonstrated that Q wave on an ECG may not be an accurate predictor for previous $\mathrm{MI}{ }^{(26-28)}$. Our results supported this information. Given the very small number of patients with a history of $\mathrm{MI}(<2 \%)$, LGE-CMR revealed the number of patients with unrecognized $\mathrm{MI}$ at approximately $15 \%$. LGE was also an independent predictor for MACE, consistent with previous reports $(26,29)$.

\section{Study Limitations}

This study had some limitations. Firstly, single-time ECG data may change dynamically during an ischemic event. However, no patient recorded chest pain during an ECG. Secondly, this study was conducted on patients with known or suspected CAD, referred for adenosine stress CMR. This may lead to a referral bias and the results may not be applicable for all patients with chronic CAD. Thirdly, we used adenosine perfusion CMR to define obstructive $C A D$ and not all patients underwent invasive coronary angiography. However, adenosine stress CMR demonstrated very high accuracy compared with invasive 
fractional flow reserve ${ }^{(30)}$. Finally, we may have missed some patients with AF that were not sent for CMR.

\section{Conclusions}

Abnormal ECG was common in patients with known or suspected chronic CAD. In a cohort of patients who had intermediate pretest probability of obstructive CAD, major ECG abnormality was associated with myocardial ischemia and provided an incremental predictive value over clinical pretest probability models. ECG also demonstrated prognosis significance in terms of future cardiovascular events in this population.

\section{Abbreviations}

$\mathrm{CAD}=$ coronary artery disease

$\mathrm{Cl}=$ confidence interval

$\mathrm{CMR}=$ cardiac magnetic resonance

$E C G=$ electrocardiography

$E F=$ ejection fraction

FOV $=$ field of view

$\mathrm{HR}=$ hazard ratio

$\mathrm{LGE}=$ late gadolinium enhancement

$\mathrm{LV}=$ left ventricular

MACE = major adverse cardiac events

$\mathrm{MI}=$ myocardial infarction

SD = standard deviation

SSFP = steady-state free precession

$\mathrm{TE}=$ echo time

$\mathrm{TR}=$ repetitive time

\section{Declarations}




\section{Ethics approval and consent to participate}

This study was approved by Siriraj Institutional Review Board (SIRB), Faculty of Medicine Siriraj Hospital, Mahidol University (Title: Prognostic value of comprehensive cardiac magnetic resonance imaging in patients with suspected coronary artery disease, certification of approval number: Si 175/2014). All methods involving human data were performed in accordance with the Declaration of Helsinki. The need for consent was waived by Siriraj Institutional Review Board (SIRB) due to its retrospective nature and as all personal identifying information was obliterated.

\section{Consent for publication}

Not applicable.

\section{Availability of data and material}

The datasets used and/or analyzed during the current study are available from the corresponding author on reasonable request.

\section{Competing interests}

The authors declare that they have no competing interests.

\section{Funding}

Faculty of Medicine Siriraj Hospital, Mahidol University, Bangkok, Thailand.

\section{Author contributions}

YK - (1) conception and design, analysis, and interpretation of data; (2) performance of experiments or therapy; (3) drafting of the manuscript or revising it critically for important intellectual content; and (4) final approval of the manuscript submitted.

RT, TS - (1) performance of experiments or therapy; (2) final approval of the manuscript submitted.

TB - (1) conception and design, analysis, and interpretation of data; (2) drafting of the manuscript or revising it critically for important intellectual content; and (3) final approval of the manuscript submitted.

\section{Acknowledgement}


The authors would like to thank Mr. Dittapol Muntham, M.S. (Statistics) for statistical assistance.

\section{References}

1. Garcia MC, Rossen LM, Bastian B, Faul M, Dowling NF, Thomas CC, et al. Potentially Excess Deaths from the Five Leading Causes of Death in Metropolitan and Nonmetropolitan Counties - United States, 2010-2017. MMWR Surveill Summ. 2019;68(10):1-11.

2. Knuuti J, Wijns W, Saraste A, Capodanno D, Barbato E, Funck-Brentano C, et al. 2019 ESC Guidelines for the diagnosis and management of chronic coronary syndromes. Eur Heart J. 2020;41(3):407-77.

3. Baskaran L, Danad I, Gransar H, B OH, Schulman-Marcus J, Lin FY, et al. A Comparison of the Updated Diamond-Forrester, CAD Consortium, and CONFIRM History-Based Risk Scores for Predicting Obstructive Coronary Artery Disease in Patients With Stable Chest Pain: The SCOT-HEART Coronary CTA Cohort. JACC Cardiovasc Imaging. 2019;12(7 Pt 2):1392-400.

4. Bittencourt MS, Hulten E, Polonsky TS, Hoffman U, Nasir K, Abbara S, et al. European Society of Cardiology-Recommended Coronary Artery Disease Consortium Pretest Probability Scores More Accurately Predict Obstructive Coronary Disease and Cardiovascular Events Than the Diamond and Forrester Score: The Partners Registry. Circulation. 2016;134(3):201-11.

5. Genders TS, Steyerberg EW, Hunink MG, Nieman K, Galema TW, Mollet NR, et al. Prediction model to estimate presence of coronary artery disease: retrospective pooled analysis of existing cohorts. BMJ. 2012;344:e3485.

6. Lee UW, Ahn S, Shin YS, Kim YJ, Ryoo SM, Sohn CH, et al. Comparison of the CAD consortium and updated Diamond-Forrester scores for predicting obstructive coronary artery disease. Am J Emerg Med. 2021;43:200-4.

7. Patel MR, Peterson ED, Dai D, Brennan JM, Redberg RF, Anderson HV, et al. Low diagnostic yield of elective coronary angiography. N Engl J Med. 2010;362(10):886-95.

8. Gurm HS, Topol EJ. The ECG in acute coronary syndromes: new tricks from an old dog. Heart. 2005;91(7):851-3.

9. Zimetbaum PJ, Josephson ME. Use of the electrocardiogram in acute myocardial infarction. N Engl J Med. 2003;348(10):933-40.

10. Auer R, Bauer DC, Marques-Vidal P, Butler J, Min LJ, Cornuz J, et al. Association of major and minor ECG abnormalities with coronary heart disease events. JAMA. 2012;307(14):1497-505.

11. Krittayaphong R, Muenkaew M, Chiewvit P, Ratanasit N, Kaolawanich Y, Phrommintikul A, et al. Electrocardiographic predictors of cardiovascular events in patients at high cardiovascular risk: a multicenter study. J Geriatr Cardiol. 2019;16(8):630-8.

12. Li Y, Dawood FZ, Chen H, Jain A, Walsh JA, 3rd, Alonso A, et al. Minor isolated Q waves and cardiovascular events in the MESA study. Am J Med. 2013;126(5):450 e9- e16.

13. Prineas R, Crow R, Blackburn H, editors. The Minnesota code manual of electrocardiographic findings: standards and procedures for measurement and classification1982. 
14. Kramer CM, Barkhausen J, Bucciarelli-Ducci C, Flamm SD, Kim RJ, Nagel E. Standardized cardiovascular magnetic resonance imaging (CMR) protocols: 2020 update. J Cardiovasc Magn Reson. 2020;22(1):17.

15. Krittayaphong R, Chaithiraphan V, Maneesai A, Udompanturak S. Prognostic value of combined magnetic resonance myocardial perfusion imaging and late gadolinium enhancement. Int $J$ Cardiovasc Imaging. 2011;27(5):705-14.

16. Schulz-Menger J, Bluemke DA, Bremerich J, Flamm SD, Fogel MA, Friedrich MG, et al. Standardized image interpretation and post-processing in cardiovascular magnetic resonance - 2020 update: Society for Cardiovascular Magnetic Resonance (SCMR): Board of Trustees Task Force on Standardized Post-Processing. J Cardiovasc Magn Reson. 2020;22(1):19.

17. Cerqueira MD, Weissman NJ, Dilsizian V, Jacobs AK, Kaul S, Laskey WK, et al. Standardized myocardial segmentation and nomenclature for tomographic imaging of the heart. A statement for healthcare professionals from the Cardiac Imaging Committee of the Council on Clinical Cardiology of the American Heart Association. Int J Cardiovasc Imaging. 2002;18(1):539-42.

18. Hicks KA, Mahaffey KW, Mehran R, Nissen SE, Wiviott SD, Dunn B, et al. 2017 Cardiovascular and Stroke Endpoint Definitions for Clinical Trials. J Am Coll Cardiol. 2018;71(9):1021-34.

19. Farhan HL, Hassan KS, Al-Belushi A, Sallam M, Al-Zakwani I. Diagnostic Value of Electrocardiographic T Wave Inversion in Lead aVL in Diagnosing Coronary Artery Disease in Patients with Chronic Stable Angina. Oman Med J. 2010;25(2):124-7.

20. Genders TS, Steyerberg EW, Alkadhi H, Leschka S, Desbiolles L, Nieman K, et al. A clinical prediction rule for the diagnosis of coronary artery disease: validation, updating, and extension. Eur Heart J. 2011;32(11):1316-30.

21. Sox HC, Jr., Garber AM, Littenberg B. The resting electrocardiogram as a screening test. A clinical analysis. Ann Intern Med. 1989;111(6):489-502.

22. Daviglus ML, Liao Y, Greenland P, Dyer AR, Liu K, Xie X, et al. Association of nonspecific minor ST-T abnormalities with cardiovascular mortality: the Chicago Western Electric Study. JAMA. 1999;281(6):530-6.

23. de Santiago A, Garcia-Lledo A, Ramos E, Santiago C. [Prognostic value of ECGs in patients with type2 diabetes mellitus without known cardiovascular disease]. Rev Esp Cardiol. 2007;60(10):1035-41.

24. Lehtonen AO, Puukka P, Varis J, Porthan K, Tikkanen JT, Nieminen MS, et al. Prevalence and prognosis of ECG abnormalities in normotensive and hypertensive individuals. J Hypertens. 2016;34(5):959-66.

25. Jeger RV, Probst C, Arsenic R, Lippuner T, Pfisterer ME, Seeberger MD, et al. Long-term prognostic value of the preoperative 12-lead electrocardiogram before major noncardiac surgery in coronary artery disease. Am Heart J. 2006;151(2):508-13.

26. Kim HW, Klem I, Shah DJ, Wu E, Meyers SN, Parker MA, et al. Unrecognized non-Q-wave myocardial infarction: prevalence and prognostic significance in patients with suspected coronary disease. PLoS Med. 2009;6(4):e1000057. 
27. Dastidar AG, Carpenter A, Rodrigues JC, Wilson CR, Kestenbaum SR, Baritussio A, et al. Role of 12 lead ECG Q-waves as a marker of myocardial infarction in the era of cardiac magnetic resonance. Journal of Cardiovascular Magnetic Resonance. 2016;18(1):P239.

28. Nadour W, Doyle M, Williams RB, Rayarao G, Grant SB, Thompson DV, et al. Does the presence of Q waves on the EKG accurately predict prior myocardial infarction when compared to cardiac magnetic resonance using late gadolinium enhancement? A cross-population study of noninfarct vs infarct patients. Heart Rhythm. 2014;11(11):2018-26.

29. Nordenskjold AM, Hammar P, Ahlstrom H, Bjerner T, Duvernoy O, Eggers KM, et al. Unrecognized Myocardial Infarction Assessed by Cardiac Magnetic Resonance Imaging-Prognostic Implications. PLoS One. 2016;11(2):e0148803.

30. Li M, Zhou T, Yang LF, Peng ZH, Ding J, Sun G. Diagnostic accuracy of myocardial magnetic resonance perfusion to diagnose ischemic stenosis with fractional flow reserve as reference: systematic review and meta-analysis. JACC Cardiovasc Imaging. 2014;7(11):1098-105.

\section{Figures}


Consecutive patients underwent adenosine stress CMR for the diagnosis and risk stratification of CAD between 2011 and 2014

$$
(\mathrm{n}=514)
$$

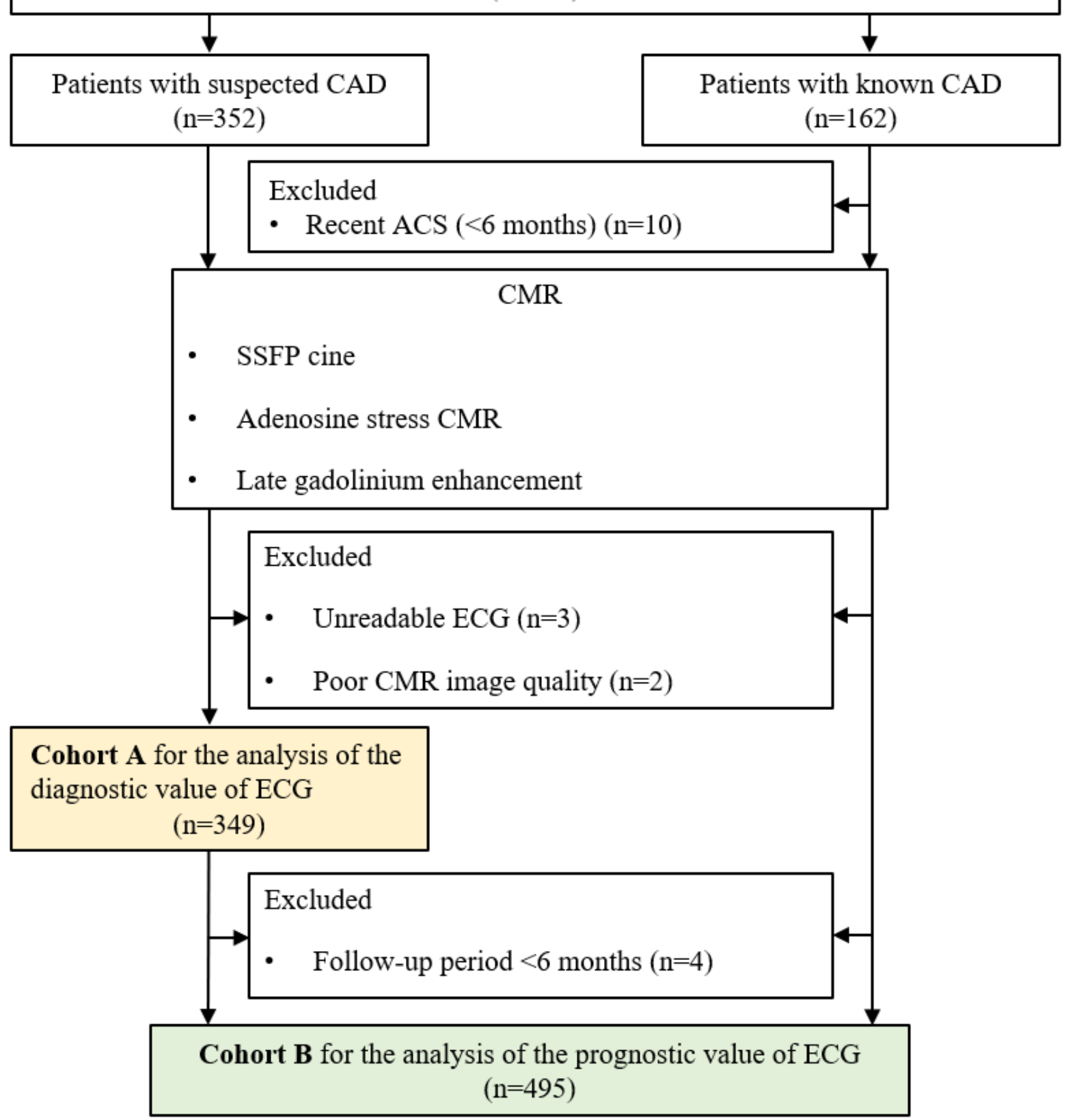

\section{Figure 1}

Study flow chart. $A C S$ = acute coronary syndrome; $C A D=$ coronary artery disease; $C M R=$ cardiac magnetic resonance; ECG = electrocardiography; SSFP = steady-state free precession. 
A

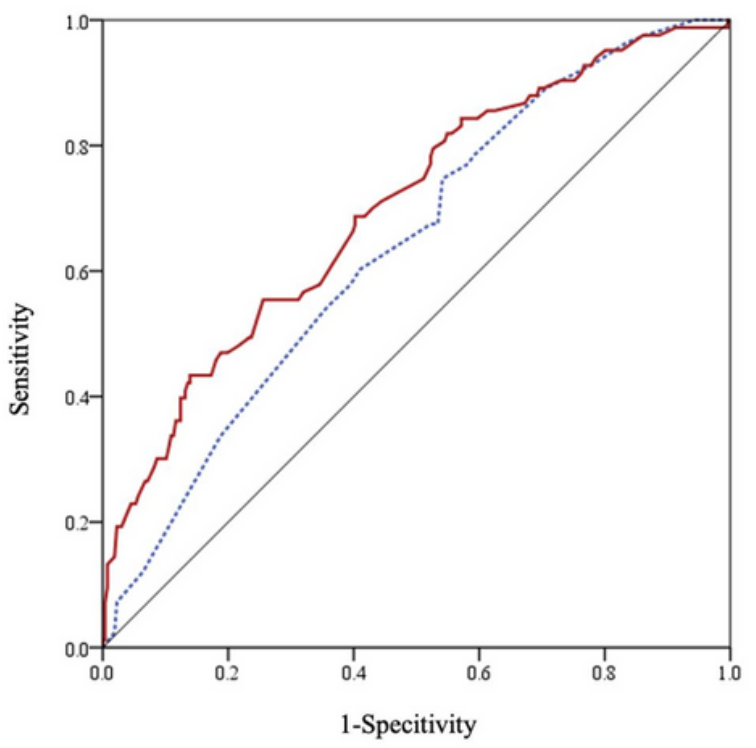

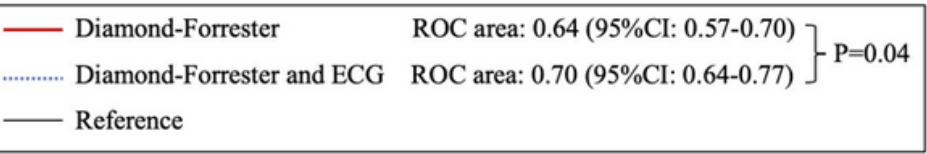

$\mathrm{B}$

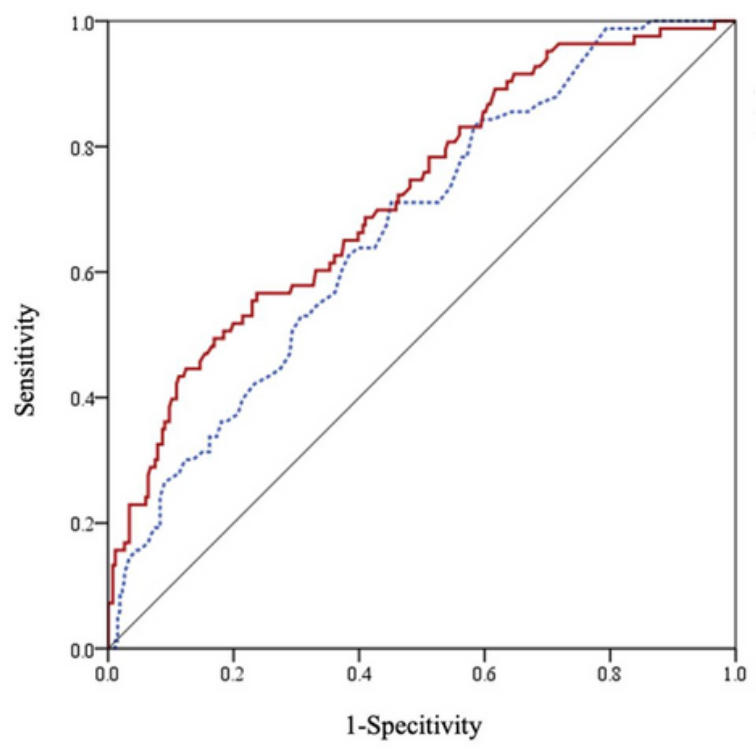

CAD consortium, clinical model $\left.\begin{array}{l}\text { ROC area: } 0.67(95 \% \mathrm{CI}: 0.61-0.73) \\ \text { ROC area: } 0.72(95 \% \mathrm{CI}: 0.66-0.79)\end{array}\right\} \mathrm{P}=0.04$ CAD consortium, clinical model and ECG Reference

\section{Figure 2}

Receiver-operating characteristics (ROC) curves for prediction of myocardial ischemia on adenosine stress perfusion CMR. A, ROC curves derived from the Diamond-Forester (DF) model (dotted blue line) and the DF model plus ECG (red line). B, ROC curves derived from the clinical model of CAD consortium (dotted blue line) and the clinical model of CAD consortium plus ECG (red line). 


\section{Major Adverse Cardiac Events}

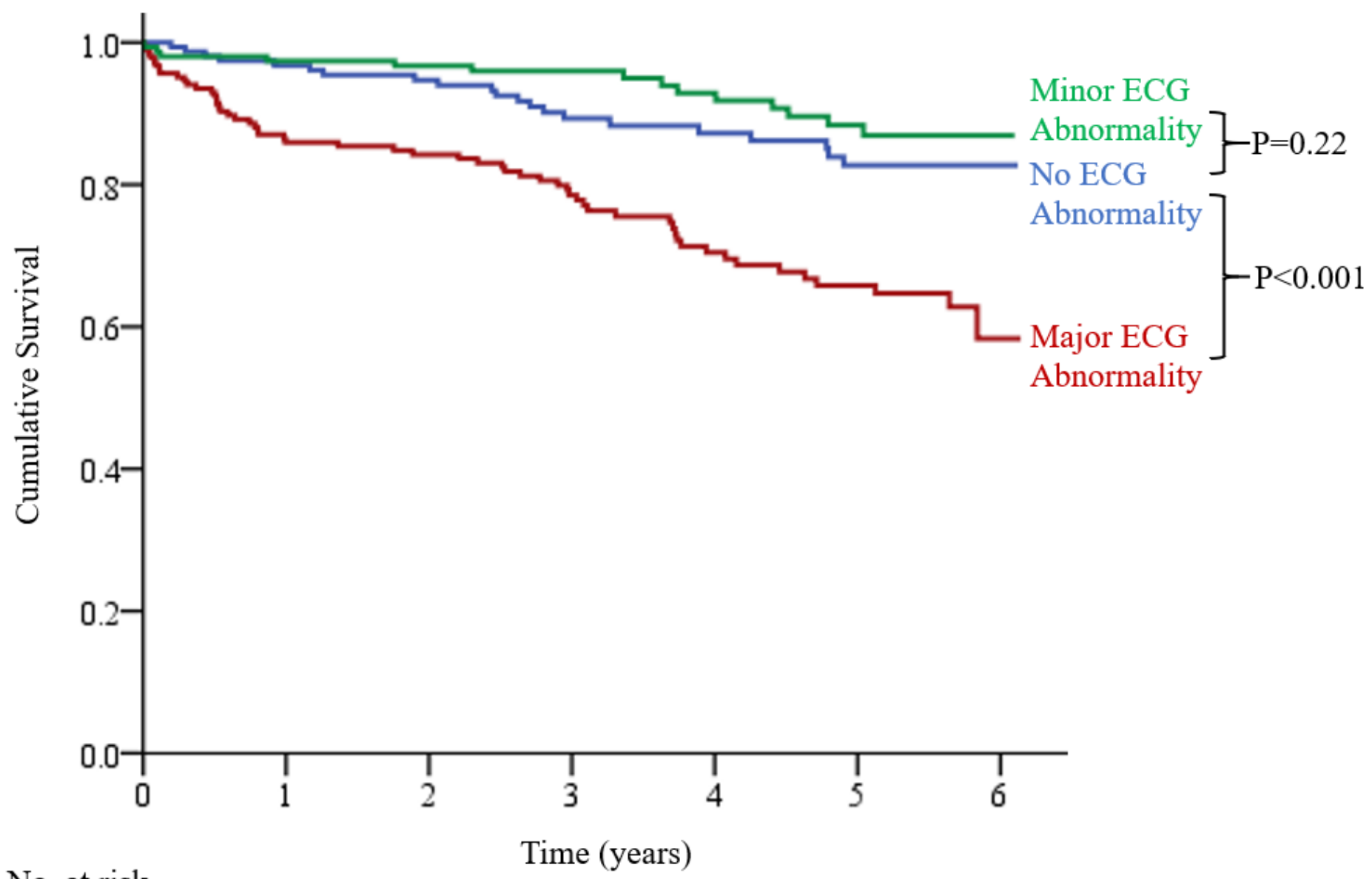

No. at risk

$\begin{array}{lllllll}154 & 150 & 139 & 112 & 87 & 60 & 5 \\ 156 & 149 & 128 & 101 & 82 & 68 & 7 \\ 185 & 159 & 145 & 113 & 80 & 63 & 8\end{array}$

\section{Figure 3}

Kaplan-Meier survival curves for major adverse cardiac events (MACE) stratified by three types of ECG. Kaplan-Meier curves demonstrate a significantly higher rate of MACE in patients with major ECG abnormality $(P<0.001)$. 


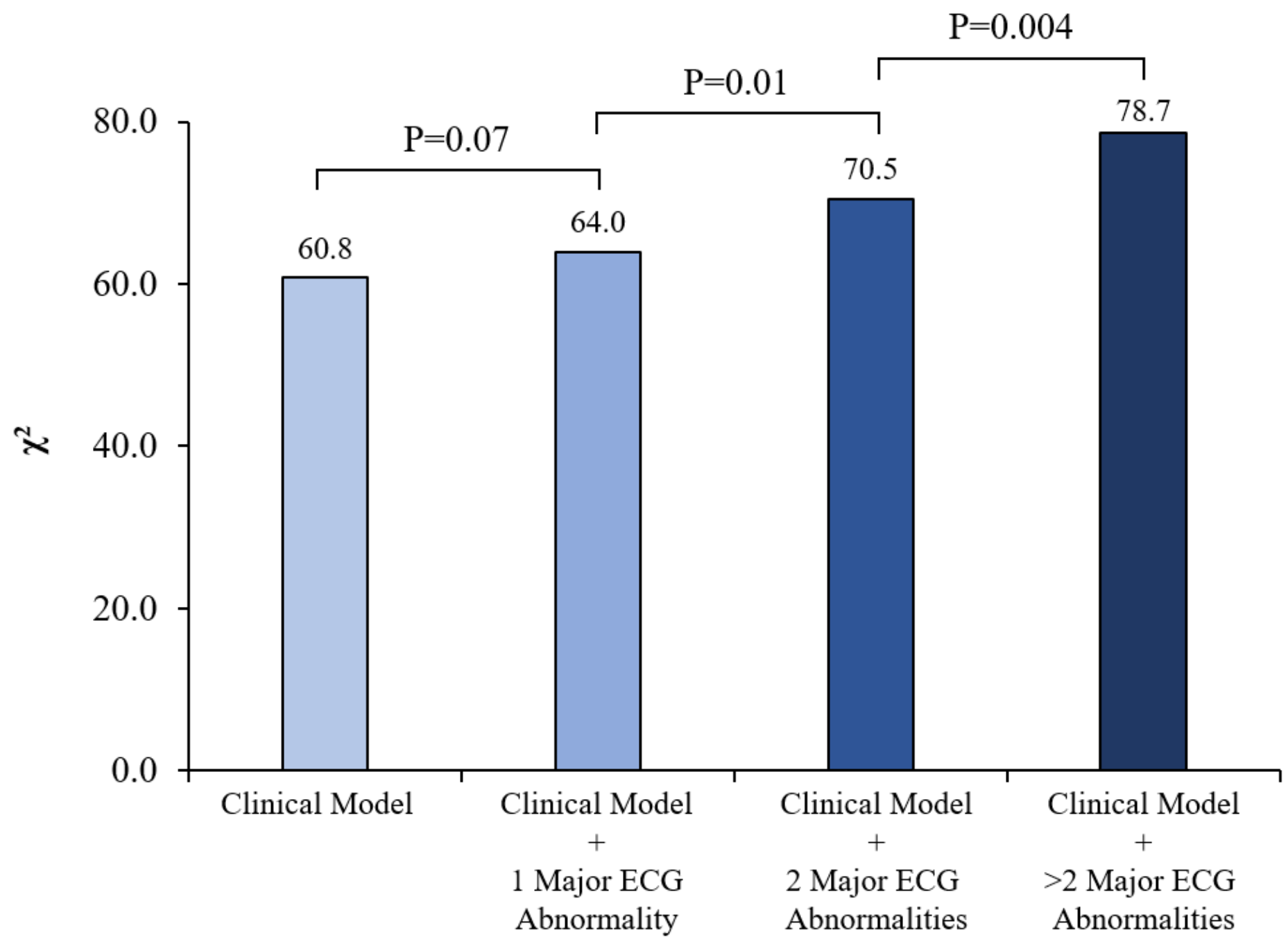

Figure 4

Incremental prognostic value of numbers of major ECG abnormalities for prediction of major adverse cardiac events (MACE). Clinical = age, male gender, history of heart failure, and prior coronary revascularization.

\section{Supplementary Files}

This is a list of supplementary files associated with this preprint. Click to download.

- 11SupplementalMaterials.docx 